\title{
Preventing Injection Drug use Initiation: State of the Evidence and Opportunities for the Future
}

\author{
Dan Werb • R. N. Bluthenthal • G. Kolla • C. Strike • \\ A. H. Kral • A. Uusküla • D. Des Jarlais
}

Published online: 25 September 2017

(C) The New York Academy of Medicine 2017

\section{Introduction}

Just over 10 years have passed since public health experts called for an update to the "infection risk reduction hierarchy" [1]. At the time Vlahov et al. noted that HIV prevention programs for people who inject drugs (PWID), $13 \%$ of whom are estimated to be HIV positive [2], should include referral to addiction treatment, increased access to sterile syringes, and education regarding the harms of syringe sharing, given that all had been proven effective at reducing the spread of injectionrelated HIV transmission [1]. However, while these interventions are critical to reducing the burden of HIV faced by active injectors, they also argued that the most effective method of preventing injection-driven HIV epidemics was to shift resources upstream, towards the prevention of injection drug use itself [1]. Since the

D. Werb $(\bowtie)$

Division of Global Public Health, Department of Medicine, University of California San Diego School of Medicine, 9500 Gilman Drive, La Jolla, CA 92093-0507, USA

e-mail: dwerb@ucsd.edu

\section{R. N. Bluthenthal}

Division of Health Behavior Research, Institute for Prevention Research, Department of Preventive Medicine, Keck School of Medicine, University of Southern California, Los Angeles, CA, USA

G. Kolla $\cdot$ C. Strike

Dalla Lana School of Public Health, University of Toronto, Toronto, ON, Canada publication of this commentary, expanded coverage of harm reduction services and the provision of sterile injecting equipment have resulted in reductions in HIV transmission among PWID in select settings. However, blood-borne disease epidemics continue to expand among PWID populations; for example, according to UNAIDS, HIV infections among PWID increased by $33 \%$ globally between 2011 and 2014 [3]. Concurrently, fatal drug overdose (often related to opioid injecting) has become a leading cause of death in both the USA and Canada [4-6]. We therefore seek to assess the state of the science on the prevention of injection initiation, to identify emerging interventional strategies, and to consider the barriers that remain in effectively controlling ongoing epidemics of injection drug use.

Since this call for an updated framework, major research studies have been undertaken to expand the

C. Strike

Centre for Addiction and Mental Health, Toronto, ON, Canada

A. H. Kral

Behavioral and Urban Health Program, RTI International, San Francisco, CA, USA

A. Uusküla

Institute of Family Medicine and Public Health, Faculty of

Medicine, University of Tartu, Tartu, Estonia

D. Des Jarlais

Edmond de Rothschild Chemical Dependency Institute,

Icahn School of Medicine at Mount Sinai,

New York City, NY, USA 
scientific understanding of injection drug use initiation (see Table 1). Indeed, research on this topic has grown from a small handful of peer-reviewed studies to a broad and increasingly comprehensive scientific literature. In short, a range of factors have been identified that appear to increase the risk that individuals will begin to inject drugs.

\section{Risk Factors for Injection Drug Use Initiation}

\section{Risk Factors for Injection Initiates}

Childhood sexual abuse and trauma [22], the noninjection use of certain drugs (including, importantly, prescription opioids) $[13,23,24]$, and behaviors such as polydrug use [25] have all been identified as individuallevel risk factors that increase the risk of injection initiation. Further, the efficiency afforded by injection vs. non-injection of drugs has been identified as a key motivator for transitions into initiation, particularly among individuals experiencing endemic poverty and during periods when the price of illegal drugs increases [26-31].

With respect to structural factors, the availability of housing and housing status (including homelessness) consistently appears as a risk factor for injection initiation across a range of settings [13, 16, 32]. For example, Roy et al. found that homelessness was the key risk factor for injection initiation among street-involved youth in Montreal. They further posited a causal pathway to injection initiation, as they note that the risk of injection initiation has been shown to be associated with the level of social integration of people who use drugs into society [33, 34], and that a lack of access to housing impacts an individual's capacity for social integration. Similarly, in a study of injection initiation in three Australian settings, Abelson et al. hypothesized that homelessness was a proxy measure for social and family disadvantage, which placed people at higher risk of initiation [35]. Indeed, the fact that much of the observational research on injection initiation is restricted to samples of street youth who experience entrenched and chronic housing instability is evidence of the strong role that housing status is assumed to play in heightening injection initiation risk.

\section{The Unique Role of "Initiators"}

As previous research has demonstrated, once an injection-naive person has decided to initiate injection, their request for assistance with their first injection can

Table 1 Chronology of selected research developments on preventing injection initiation

\begin{tabular}{|c|c|c|}
\hline Year & Development & Research outcomes \\
\hline 1988-1992 & "Heroin sniffer" intervention studies & $\begin{array}{l}\text { Casriel et al. [7] } \\
\text { Casriel et al. [8] } \\
\text { Des Jarlais et al. [9] }\end{array}$ \\
\hline 1998-1999 & "Break the Cycle" intervention studies & $\begin{array}{l}\text { Hunt et al. [10] } \\
\text { Hunt et al. [11] }\end{array}$ \\
\hline $2001-2003$ & Montreal street youth cohort & $\begin{array}{l}\text { Roy et al. [12] } \\
\text { Roy et al. [13] }\end{array}$ \\
\hline 2004 & Commentary: Updating the infection risk reduction hierarchy & Vlahov et al. [1] \\
\hline 2006 & At-Risk Youth Study (ARYS) in Vancouver & Wood et al. [14] \\
\hline 2010 & Route transition interventions literature review & Bridge [15] \\
\hline 2011 & California PWID cohort to investigate injection initiators & $\begin{array}{l}\text { Kral et al. [16] } \\
\text { Bluthenthal et al. [17] }\end{array}$ \\
\hline 2013 & Interventions to prevent the initiation of injection drug use: a systematic review & Werb et al. [18] \\
\hline 2014 & "Change the Cycle" intervention & Strike et al. [19] \\
\hline 2015 & Next steps in research on injection initiation incidence and prevention & Bluthenthal and Kral [20] \\
\hline 2015 & US NIDA Avant Garde Award: "Combined prevention to reduce initiation into injecting drug use" & Forthcoming \\
\hline 2015 & US NIDA Avenir Award: "Preventing injecting by modifying existing responses" & Werb et al. [21] \\
\hline 2015 & US NIDA R01: "Preventing injection initiation: the Change the Cycle randomized controlled trial" & Forthcoming \\
\hline
\end{tabular}


be persistent [36]. Therefore, preventing transitions into injecting should address both the need to prevent people from seeking out injecting and the need to prevent PWID from initiating others into this behavior. One way to address both of these factors is by reducing exposure to, and positive modeling of, injecting behaviors among injection-naive persons. This is likely needed because the existing empirical literature demonstrates that not only is exposure to injection drug use associated with initiation episodes [13, 24, 28, 36-38] but also because these behaviors are associated with requests for initiation made by injection-naive persons [17]. This suggests that injection drug use can be defined as a behavior influenced by interpersonal, group, and broader social processes (with some experts characterizing it as a socially communicable process [28]). As such, events and approaches that increase population mixing between PWID and non-injection drug-using populations may also increase the incidence of injection initiation. Specifically, studies of people who facilitate initiation suggest that they are generally more experienced with injecting [39] and have been exposed to or interacted intimately with other PWID as a result of homelessness or incarceration [13]. These intimate interactions with PWID that lead to injection initiation range, according to the literature, from family members, inmates within prison settings, "hit doctors" (i.e., individuals who assist others with injection for a fee), sexual partners, drug dealers, and friends [24, 40-44]. Further, evidence suggests that the role of "initiator" is often integrated into other drug scene roles such as providing safer injecting education or assistance with injections [39]. For these reasons, the exposure of injection-naive persons to injection drug use and related behaviors appears to be the most critical risk factor for injection initiation.

\section{Pathways to Initiation by People Who Inject Drugs}

Data also suggest that the association between injection exposure and initiation does not appear to follow a single causal pathway. Instead, the research to date suggests that exposure to injecting and initiation may be associated in multiple ways: injection-naive persons may observe injection or hear PWID speak positively about it [19, 24, 37]; PWID may act as sources of injection education [19, 28]; and PWID may also directly assist individuals with injection during their initiation events $[39,45]$.
Incidence of Initiation of Others by People Who Inject Drugs

While a minority of PWID report ever facilitating injecting initiation events (self-reported prevalence in studies varies from 17 to $47 \%$ ) [39, 46], those who do may initiate multiple individuals. However, estimates of the number of initiates per initiator (i.e., the level of communicability per individual PWID) vary. For example, recent research in California found that, among a sample of 605 PWID, 204 participants (35\%) reported initiating a total of 3271 individuals into injecting during their lifetime; this is equal to a mean of 15.5 initiates per PWID [45]. Meanwhile, among a sample of 324 Australian PWID, 55 reported initiating 128 individuals in the last 5 years, for a mean of 2.3 per PWID [39]. In Toronto, Canada, among a sample of 98 PWID, 27.4\% reported initiating others in their lifetime; the median number of people they reported initiating was 2 , with $56 \%$ reporting having initiated between 2 and 4 people [47].

\section{Implications for Preventing Injection Drug Use Initiation}

In epidemiologic parlance, the drug-related, psychosocial, and structural factors listed in "Risk Factors for Injection Initiates" section above appear to be contributory causes of injection initiation. A contributory cause refers to a factor that, if altered, may influence an outcome but is not in and of itself sufficient or necessary to cause the outcome [48]. This is because while research has identified some of the psychosocial and drug-related factors that may increase the risk of injection initiation, many people who experience these factors (e.g., trauma, childhood sexual abuse, street-involvement, homelessness, non-injection heroin, or cocaine use) do not, in fact, ever initiate drug injecting. Indeed, individuals who inject drugs will not necessarily experience all or even some of these behaviors or conditions prior to their initiation of injecting. By contrast, there is a nearconsensus across scientific studies that exposure to injection drug use is a key risk factor for injection initiation (though it appears an insufficient cause in isolation) $[19,21,24$, 40-44].

The growing understanding of these mechanisms has two major implications for the prevention of HIV and viral hepatitis. First, now that we have a relatively comprehensive understanding of the risk factors for injecting initiation, as well as effective comprehensive HIV prevention packages [49], allocating resources 
towards developing evidence-based interventions to prevent injection initiation is likely necessary to amplify existing efforts to prevent the spread of injection-related HIV and viral hepatitis transmission. Second, interventions to prevent injection initiation are likely to be effective if they engage with PWID to reduce the risk that they expose others to injecting, given the multiple pathways to injecting initiation involving PWID.

\section{Interventions to Prevent Injection Drug Use Initiation}

\section{Behavioral Interventions}

An increasing number of interventions are therefore seeking to prevent the incidence of injecting initiation by focusing on the role of active PWID in exposing others to injecting. These have, to date, consisted primarily of behavioral interventions. Break the Cycle, for instance, engages PWID in one-on-one education and training sessions involving current drug intervention or outreach workers and aims to increase PWID's awareness of the potential effects of exposure to injecting on the desire to initiate injection among injection-naive drug users, while also equipping them with strategies to refuse initiation requests [10]. Break the Cycle has demonstrated significant reductions in PWID, reporting that they have exposed injection-naive persons to injecting or assisted with a first injection [10]. An adaption of Break the Cycle, named Change the Cycle, was recently developed and evaluated in Canada, with a focus on both injection initiation prevention and safer injection training for active PWID. It was found to significantly reduce participants' exposure or encouragement of injecting to injection-naive persons, as well as the total number of initiations performed by participants [33]. A randomized controlled trial of the Change the Cycle intervention is currently underway in California (Bluthenthal, Kral, and Strike: NIDA R01 DA038965).

Other interventions have also sought to directly intervene with infrequent and non-injectors to delay or prevent transition into habitual injection drug use. For instance, a randomized control trial on injecting prevention tested the impact of a peer-based behavioral intervention among "heroin sniffers" [9]. The intervention, consisting of a four-session group-based social learning program, was found to be significantly associated with a reduced likelihood of subsequent injecting initiation. Importantly, this interventional effect remained significant in a multivariate model adjusting for participants reporting having a close relationship with a PWID [9]. The testing of a combination intervention consisting of the "heroin sniffers" (i.e., delaying habitual injecting) and Break the Cycle (e.g., reducing PWID involvement in injection initiation of others) projects, along with lowthreshold substance use and therapy for injectingdiscordant couples, will also soon be carried out in New York City and Tallinn, Estonia (Des Jarlais; NIDA DP1 DA039542).

Emerging Structural Approaches to Injection Initiation Prevention

Along with the development of behavioral interventions, there is a growing recognition that structural and environmental factors play a role in heightening the risk that individuals initiate injecting. As noted above, prison environments have been identified as sites of injection initiation, as these environments facilitate (often sustained) population mixing between PWID and noninjection drug-using populations [50]. Low availability of stable housing for PWID and injection-naive people who use drugs may result in their shared use of shooting galleries or other drug use venues, thereby increasing the risk of exposure to injecting and, ultimately, initiation of this behavior [13]. Clearly, the level of access that PWID have to public health programming and ancillary services is likely to influence their risk of exposing others to injection, and this topic is the focus of a six-city longitudinal study (Werb: NIDA DP2 DA040256-01); this study, named PRIMER (Preventing Injecting by Modifying Existing Responses), pools data from cohort studies of PWID from Vancouver (Canada), San Diego (USA), Tijuana (Mexico), as well as Marseille, Paris, and Bordeaux (France) and seeks to determine whether housing status, a history of incarceration, enrolment into medication-assisted therapy (MAT), and medically supervised injection facilities (SIF) access impact the risk that PWID initiate others into injecting [21]. Characterizing the influence of these on the risk that PWID expose and initiate injectionnaive individuals can then provide policymakers with critical evidence on how scaling up existing structural interventions known to reduce injection-related risk behaviors may also prevent the incidence of injection initiation [51]. 


\section{Optimizing Injection Drug Use Prevention Approaches}

Addressing the risk that exposure to injecting poses for populations at risk of injection initiation appears broadly consistent with, and complementary to, the current goals of HIV prevention [49]. For example, clients of SIF are generally restricted to people who inject drugs, which may reduce the risk of exposing injection-naive individuals to injecting in the community.

Much of the data collected to date on injecting initiation comes from North American and Western European settings, despite the existence of syndemics of injecting, HIV, and viral hepatitis globally. As such, interventional responses must be adaptable and tailored to local cultural contexts to ensure maximum effectiveness. In Estonia, for example, $35 \%$ of a sample of PWID $(n=350)$ reported sharing syringes/needles, while $86 \%$ reported engaging in unprotected sex [52]. Concurrently, there is widespread lack of coverage for basic HIV prevention interventions such as MAT [53]; as a result, in certain regions (i.e., Russian Federation), the elevated incidence of HIV and other blood-borne disease transmission among PWID is likely to continue [2]. The lack of education and experience with the harmful consequences of injecting drugs among at-risk populations in Eastern Europe may have contributed to the expansion of these syndemics, though it is likely that a more stable economic climate and a "community learning" effect may be contributing to a recent increase in the resilience of these populations in avoiding injecting [54]. While studies from the region document some decreases in the proportion of new injectors among PWID populations [54], HIV and HCV prevalence among new injectors remains high [53].

Beyond the need to consider regional differences in the development of interventions to prevent injection initiation, it is also critical to avoid a simplistic formulation of a first injection as an irreversible change in behavior. A first injection does not mean that the person will be irrevocably committed to injecting as his or her dominant route of drug administration for the indefinite future, or that they will even continue to use drugs. By contrast, studies of "former injectors" and persons who injected for varying lengths of time and then "reverse transitioned" back to non-injecting drug use demonstrate the fluidity of injection drug use careers [55]. At present, we do not have an in-depth understanding of the factors associated with reverse transitions, but the data collected to date clearly demonstrate that many people who transitioned from injecting to non-injecting modes of administration avoid relapsing back to injecting for long periods of time or may never begin to inject regularly. As such, interventions that support reverse transitions among persons who continue to use drugs are likely to be highly complementary to efforts to prevent injecting initiation.

\section{Barriers to Effectively Preventing Injection Initiation}

While a dedicated effort to preventing injection initiation can meaningfully contribute to global HIV and viral hepatitis prevention, many aspects of such a strategy must be carefully considered. First, an injection initiation prevention strategy should be integrated with the existing suite of comprehensive HIV prevention programs to ensure its effectiveness [49], given the overlap between the behavioral and structural factors that influence injection initiation and those that influence injection-related HIV transmission risk. Second, research on the experiences of individuals who initiate others into injection suggests that while interventions to prevent this phenomenon are likely to be wellreceived by PWID in general, they are unlikely to prevent all incident cases of injection initiation due to the multiple social processes influencing this phenomenon $[28,56]$. In light of this limitation, integrating safer injection education components into injection initiation prevention interventions (as was done in the Change the Cycle pilot) may, in the absence of reducing initiation incidence risk to zero, delay or prevent HIV and viral hepatitis transmission among newly initiated PWID, who represent a group at extremely high risk of infection [57]. Third, preventing injection initiation will require a reconsideration of the key populations for HIV prevention. Specifically, while PWID are implicated in injection initiation events, research to date has delineated those populations at greatest risk of initiating; these should be meaningfully considered within broader prevention efforts [20]. Fourth, a global strategy to prevent injection will necessarily require multisite investigations to determine how best to optimize prevention strategies to local dynamics and discrete policy environments, including low-, middle-, and upper-income settings. Fifth, it is imperative that community and public health-oriented platforms be developed to deliver 
interventions to persons at high risk of injection initiation, considering that existing approaches that provide services for PWID, such as NSPs and MAT, do not generally attract injection-naive people who use drugs. This concern applies also to programs that treat substance use disorders, which necessarily focus on reducing drug use; staff may therefore not be trained in (or may be philosophically opposed to) reducing injecting initiation, particularly if the treatment program is abstinence-focused. Similarly, considerations of peer to peer injection education interventions as potential models of injection prevention may need to be considered [58]. Finally, emerging approaches must not repeat the failures of past prevention efforts, which have unsuccessfully used as a tool to bolster anti-drug social norms [59, $60]$. Beyond avoiding a repetition of past ineffectiveness, future interventions must also ensure that they do not inadvertently increase the stigma around drug injecting while seeking to prevent this behavior. While obvious tensions exist between these two goals, they can be balanced by ensuring that prevention efforts recognize that the vast majority of PWID report an unwillingness to initiate others but nevertheless find themselves unable to avoid doing so as a result of constraining socioeconomic contexts [21, 41, 61].

\section{Conclusions}

The scientific understanding of injection initiation has greatly evolved over the past decade and has been accompanied by a renewed focus on its prevention by HIV scientists and funding bodies alike [62, 63]. We can therefore state with some confidence that the prioritization of the prevention of injection initiation, as called for by experts over a decade ago [1], has edged closer to reality. However, important issues remain, largely related to the low levels of access that drug-using populations currently have to a range of HIV prevention interventions including opioid substitution therapy, medically supervised injection facilities, and needle and syringe programs [64], as well as the lack of development, evaluation, and scale-up of interventions to prevent injection initiation [18]. A prevention strategy that does not unintentionally undermine the twin goals of harm reduction and prevention of injection initiation is therefore needed.

With an emerging body of evidence on the factors that influence injection initiation, which include the multiple individual-level and structural-level approaches that have been developed and are being investigated, the suite of options available to public health experts and policymakers to prevent this phenomenon is becoming clearer. We therefore call on the scientific community to engage in this next "upstream" phase of HIV prevention as part of the global effort to control the unacceptably high risk of morbidity and mortality posed by injection drug use at a time of great worldwide advances in HIV and viral hepatitis prevention [65].

Acknowledgments Dan Werb is supported by a US National Institute on Drug Abuse Avenir Award (DP2 DA040256-01) and a Canadian Institutes of Health Research New Investigator Award. Gillian Kolla is supported by a Canadian Institutes of Health Research Banting and Best Doctoral Research Award. Ricky Bluthenthal and Alex Kral are supported by the National Institute on Drug Abuse grants (R01 DA038965 and R01 DA027689). Don Des Jarlais is supported by a US National Institute on Drug Abuse Avant Garde Award (DP1 DA039542-02).

\section{References}

1. Vlahov D, Fuller CM, Ompad DC, Galea S, Des Jarlais DC. Updating the infection risk reduction hierarchy: preventing transition into injection. J Urban Health. 2004;81(1):14.

2. UNAIDS. The Gap report. Geneva: Joint United Nations Programme on HIV/AIDS; 2014.

3. UNAIDS. Stopping the rise of new HIV infections among people who inject drugs. 2017. http://www.unaids. org/en/resources/presscentre/featurestories/2017 /march/20170316 CND (Accessed 2 July 2017).

4. Katz J. Drug deaths in America are rising faster than ever. The New York Times 2017.

5. Proctor J, Larsen K. 'An exceptionally high toll': fentanyl, overdoses claim 488 in B.C. CBCca. CBC/Radio-Canada: Toronto, ON. 2016

6. Gomes T, Mamdani MM, Dhalla IA, Cornish S, Paterson JM, Juurlink DN. The burden of premature opioid-related mortality. Addiction. 2014;109(9):1482-8.

7. Casriel C, Rockwell R, Stepherson B. Heroin sniffers: between two worlds. J Psychoactive Drugs. 1988;20(4):43740.

8. Casriel C, Des Jarlais DC, Rodriguez R, Friedman SR, Stepherson B, Khuri E. Working with heroin sniffers: clinical issues in preventing drug injection. J Subst Abus Treat. 1990;7(1):1-10.

9. Des Jarlais CD, Casriel C, Friedman SR, Rosenblum A. AIDS and the transition to illicit drug injection: results of a randomized trial prevention program. Br J Addict. 1992;87(3):6.

10. Hunt N, Stillwell G, Taylor C, Griffiths P. Evaluation of a brief intervention to prevent initiation into injecting. Drug Educ Prev Policy. 1998;5(2):185-94. 
11. Hunt PG. Mathew Southwell, Garry Stillwell, John Strang, Neil. Preventing and curtailing injecting drug use: a review of opportunities for developing and delivering'route transition interventions. Drug Alcohol Rev. 1999;18(4):441-51.

12. Roy E, Haley N, Leclerc P, Cedras L, Boivin JF. Drug injection among street youth: the first time. Addiction. 2001;97:1003-9.

13. Roy E, Haley N, Leclerc P, Cedras L, Blais L, Boivin JF. Drug injection among street youths in Montreal: predictors of initiation. J Urban Health. 2003;80(1):92.

14. Wood E, Stolz J-A, Montaner JISG, Kerr T. Evaluating methamphetamine use and risks of injection initiation among street youth: The ARYS study. Harm Reduct J. 2006;3(18):1.

15. Bridge J. Route transition interventions: potential public health gains from reducing or preventing injecting. Int $J$ Drug Policy. 2010;21(2):125-8.

16. Kral A, Wenger $\mathrm{L}, \mathrm{Chu} \mathrm{D}$, et al. Initiating people into illicit drug injection. Drug Alcohol Depend. 2015;146:e164.

17. Bluthenthal RN, Wenger L, Chu D, et al. Factors associated with being asked to initiate someone into injection drug use. Drug Alcohol Depend. 2015;149:252-8.

18. Werb D, Buxton J, Shoveller J, Richardson C, Rowell G, Wood E. Interventions to prevent the initiation of injection drug use: a systematic review. Drug Alcohol Depend. 2013;133(2):669-76.

19. Strike C, Rotondi M, Kolla G, et al. Interrupting the social processes linked with initiation of injection drug use: results from a pilot study. Drug Alcohol Depend. 2014;137:48-54.

20. Bluthenthal RN, Kral AH. Next steps in research on injection initiation incidence and prevention. Addiction. 2015;110(8):1258-9.

21. Werb D, Garfein R, Kerr T, et al. A socio-structural approach to preventing injection drug use initiation: rationale for the PRIMER study. Harm Reduct J. 2016;13:25.

22. Hadland SE, Werb D, Kerr T, et al. Childhood sexual abuse and risk for initiating injection drug use during adolescence and young adulthood: a prospective cohort study. $J$ Adolesc Health. 2012;50(2):S1.

23. Young AM, Havens JR. Transition from first illicit drug use to first injection drug use among rural Appalachian drug users: a cross-sectional comparison and retrospective survival analysis. Addiction. 2012;107(3):587-96.

24. Werb D, Kerr T, Buxton J, et al. Crystal methamphetamine and injecting initiation among street-involved youth in a Canadian setting. CMAJ. 2013;185(18):1569-75.

25. Trenz RC, Scherer M, Harrell P, Zur J, Sinha A, Latimer W. Early onset of drug and polysubstance use as predictors of injection drug use among adult drug users. Addict Behav. 2012;37(4):367-72.

26. Strathdee SA, Zafar T, Brahmbhatt H, Baksh A, ul Hassan S. Rise in needle sharing among injection drug users in Pakistan during the Afghanistan war. Drug Alcohol Depend. 2003;71(1):17.

27. Guise A, Dimova M, Ndimbii J, Clark P, Rhodes T. A qualitative analysis of transitions to heroin injection in Kenya: implications for HIV prevention and harm reduction. Harm Reduct J. 2015;12(1):27.

28. Harocopos A, Goldsamt LA, Kobrak P, Jost JJ, Clatts MC. New injectors and the social context of injection initiation. Int J Drug Policy. 2009;20(4):317-23.
29. Kermode M, Longleng V, Singh BC, Bowen K, Rintoul A. Killing time with enjoyment: a qualitative study of initiation into injecting drug use in north-east India. Subst Use Misuse. 2009;44(8):1070-89.

30. Khobzi N, Strike C, Cavalieri W, et al. A qualitative study on the initiation into injection drug use: necessary and background processes. Addict Res Theory. 2009;17(5):546-59.

31. Dertadian GC, Maher L. From oxycodone to heroin: two cases of transitioning opioid use in young Australians. Drug Alcohol Rev. 2014;33(1):102-4.

32. Feng C, DeBeck K, Kerr T, Mathias S, Montaner J, Wood E. Homelessness independently predicts injection drug use initiation among street-involved youth in a Canadian setting. $J$ Adolesc Health. 2013;52(4):499-501.

33. Sotheran JL, Goldsmith DS, Blasco M, Friedman SR. Heroin sniffing as self-regulation among injecting and non-injecting heroin users. J Drug Issues. 1999;29(2): 401-21.

34. Neaigus A, Atillasoy A, Friedman SR, et al. Trends in the noninjected use of heroin and factors associated with the transition to injecting. In: Inciardi JA, Harrison LD, editors. Drugs, health, and social policy series, Vol. 6. Heroin in the age of crack-cocaine. Thousand Oaks: Sage Publications; 1988. p. 131-59.

35. Abelson J, Treloar C, Crawford J, Kippax S, van Beek I, Howard J. Some characteristics of early-onset injection drug users prior to and at the time of their first injection. Addiction. 2006;101(4):548-55.

36. Bryant J, Bryant J, Treloar C, Bryant J, Treloar C. The gendered context of initiation to injecting drug use: evidence for women as active initiates. Drug Alcohol Rev. 2007;26(3): 287-93.

37. Chami G, Werb D, Feng C, DeBeck K, Kerr T, Wood E. Neighborhood of residence and risk of initiation into injection drug use among street-involved youth in a Canadian setting. Drug Alcohol Depend. 2013;132(3):486-90.

38. Rahimi-Movaghar A, Amin-Esmaeili M, Shadloo B, Noroozi A, Malekinejad M. Transition to injecting drug use in Iran: a systematic review of qualitative and quantitative evidence. Int J Drug Policy. 2015;26(9):808-19.

39. Bryant J, Treloar C. Initiators: an examination of young injecting drug users who initiate others to injecting. AIDS Behav. 2008;12(6):885-90.

40. Doherty MC, Edgar Monterroso MDMPH. Gender differences in the initiation of injection drug use among young adults. J Urban Health. 2000;77(3):396-414.

41. Small W, Fast D, Krusi A, Wood E, Kerr T. Social influences upon injection initiation among street-involved youth in Vancouver, Canada: a qualitative study. Subst Abuse Treat Prev Policy. 2009;4(1):1.

42. Draus PJ, Carlson RG. Needles in the haystacks: the social context of initiation to heroin injection in rural Ohio. Subst Use Misuse. 2006;41(8):1111-24.

43. Nasir S, Rosenthal D. The social context of initiation into injecting drugs in the slums of Makassar, Indonesia. Int $J$ Drug Policy. 2009;20(3):237-43.

44. Ouellet LJ, Rahimian A, Wiebel WW. The onset of drug injection among sex partners of injection drug users. AIDS Educ Prev. 1998;10(4):341. 
45. Bluthenthal RN, Wenger L, Chu D, Quinn B, Thing J, Kral AH. Factors associated with initiating someone into illicit drug injection. Drug Alcohol Depend. 2014;144:186-92.

46. Crofts N, Louie R, Rosenthal D, Jolley D. The first hit: circumstances surrounding initiation into injecting. Addiction. 1996;91(8):1187-96.

47. Rotondi NK, Strike C, Kolla G, et al. Transition to injection drug use: the role of initiators. AIDS Behav. 2014;18(3):48694.

48. Riegelman R. Contributory cause: unnecessary and insufficient. Postgrad Med. 1979;66(2):177-9.

49. WHO. Tools to set and monitor targets for HIV prevention, diagnosis, treatment and care for key populations: Supplement to the 2014 consolidated guidelines for HIV prevention, diagnosis, treatment and care for key key populations. Geneva: World Health Organization; 2015.

50. Gore SM, Bird AG, Ross AJ. Prison rites: starting to inject inside. BMJ. 1995;311(7013):1135-6.

51. Vashishtha D, Mittal ML, Werb D. The North American opioid epidemic: current challenges and a call for treatment as prevention. Harm Reduct J. 2017;14(1):7.

52. Uusküla et al. Unpublished data.

53. Mathers BM, Degenhardt L, Ali H, et al. HIV prevention, treatment, and care services for people who inject drugs: a systematic review of global, regional, and national coverage. Lancet. 2010;375(9719):15.

54. Uusküla A, Rajaleid K, Talu A, Abel-Ollo K, Des Jarlais DC. A decline in the prevalence of injecting drug users in Estonia, 2005-2009. Int J Drug Policy. 2013;24(4):312-8.

55. Genberg BL, Gange SJ, Go VF, Celentano DD, Kirk GD, Mehta SH. Trajectories of injection drug use over 20 years (1988-2008) in Baltimore, Maryland. Am J Epidemiol. 2011;173(7):829-36.

56. Kolla G, Strike C, Roy É, et al. Initiation stories: an examination of the narratives of people who assist with a first injection. Subst Use Misuse. 2015;50:1-9.
57. Garfein RS, Vlahov D, Galai N, Doherty MC, Nelson KE. Viral infections in short-term injection drug users: the prevalence of the hepatitis $\mathrm{C}$, hepatitis B, human immunodeficiency, and human T-lymphotropic viruses. Am J Pub Health. 1996;86(5):655.

58. Small W, Wood E, Tobin D, Rikley J, Lapushinsky D, Kerr T. The injection support team: a peer-driven program to address unsafe injecting in a Canadian setting. Subst Use Misuse. 2012;47(5):491-501.

59. Werb D, Mills EJ, DeBeck K, Kerr T, Montaner JSG, Wood E. The effectiveness of anti-illicit-drug public-service announcements: a systematic review and meta-analysis. $J$ Epidemiol Commun Health. 2011;65:7.

60. West S, O'Neal K. Project D.A.R.E. outcome effectiveness revisited. Am J Pub Health. 2004;94(6):1027.

61. Rhodes T, Bivol S, Scutelniciuc O, Hunt N, Bernays S, Busza J. Narrating the social relations of initiating injecting drug use: transitions in self and society. Int J Drug Policy. 2011;22(6):445-54.

62. National Institute on Drug Abuse. 2015 Avant-Garde Awards offer extraordinary ideas in HIV/AIDS research 2015. http://www.drugabuse.gov/news-events/news-releases/2015 /02/2015-avant-garde-awards-offer-extraordinary-ideas-inhivaids-research (Accessed 3 July 2015).

63. National Institute on Drug Abuse. Avenir Award Winners. 2015. http://www.drugabuse.gov/news-events/aveniraward-winners (Accessed 3 July 2015).

64. Degenhardt L, Mathers BM, Wirtz AL, et al. What has been achieved in HIV prevention, treatment and care for people who inject drugs, 2010-2012? A review of the six highest burden countries. Int J Drug Policy. 2014;25(1):53-60.

65. WHO. Antiretroviral treatment as prevention (TasP) of HIV and TB: 2012 update. Geneva: World Health Organization; 2012. 